Effect of Complex Training on Jumping Variables During

Heading the Ball for Soccer Players 


\title{
Effect of Complex Training on Jumping Variables During Heading the Ball for Soccer Players
}

\begin{abstract}
:
The aim of research is to investigate the effect complex training on squat jump height (SJ), countermovement jump height (CMJ), ground contact time (GCT), jumping height during heading the ball (JHDH), total flight time (TFT), time to reach maximum height (TMH), and initial velocity (IV) during heading the ball from jumping. Experimental method was applied on a sample of 10 soccer players (mean +/- SD: $20.7+/-1.2$ years, $176.5+/-7.3 \mathrm{~cm}, 76.5+/-6.7 \mathrm{~kg}$ ) by applying pre- and post-measurements. SJ, CMJ, and heading the ball from jumping tests were applied on the subjects respectively. Tests were recorded using a high frequency video camera (GoPro 3ed, $240 \mathrm{fps}$ ) and analyzed using (Tracker 4.96 video analysis and modeling tool). Eight week complex training program was applied 3 times a week. Results show significant differences between pre and post measurements in $\mathrm{SJ}(\mathrm{t}=11.78), \mathrm{CMJ}(\mathrm{t}=6.30), \mathrm{GCT}(\mathrm{t}=5.56), \mathrm{JHDH}(\mathrm{t}=5.05)$, TFT $(\mathrm{t}=-4.895)$, TMH $(\mathrm{t}=4.895)$, and IV $(\mathrm{t}=-4.895)(p<0.05)$ for post measurements. Present results recommend involving complex training in the specific preparation phase for soccer players. We could conclude that complex training program increases vertical jumping performances and decrease GCT and TMH by inducing motor unit recruitment and stored energy in the muscle tendon unite during the shortening phase of the stretchshortening cycle.
\end{abstract}

Key words: Complex training, Plyometric training, Post-activation potentiation 


\section{INTRODUCTION:}

The movement, where acceleration occurs through its full range -resulting in higher speeds and power outputs- can be described as a power-oriented movement (Newton et al., 1997; Newton, Kraemer, Häkkinen, Humphries, \& Murphy, 1996; Wilson, Wood, \& Elliott, 1991). Therefore, Power considered to be a substantial and crucial aspect of successful performance in various sports that demand speed, agility, and explosive action (Docherty, Robbins, \& Hodgson, 2004). Soccer skills involving shooting, sprinting and jumping require a high amount of power output rather than high force production of the involved muscles. In this regard, around $80 \%$ of scored goals in soccer games are achieved by at least one powerful move like shooting, assisting with a short or long distance pass, jumping trying to reach maximum height to score with the head, or rapid change in directions in various goal situations in professional soccer (Faude, Koch, \& Meyer, 2012). Accordingly, players and coaches are trying to adjust training programs in order to develop explosive power rather than primarily maximal muscle strength (Newton et al., 1996). Fleck and Kontor 1986 in their first peer-reviewed article described complex training as a way of training that combines in pairs between a heavy resistant exercises with a similar biomechanical lighter exercise (Fleck \& Kontor, 1986). Complex training (CT) is an efficient method of training which alternates between a heavy load resistance exercises followed by a biomechanically similar explosive plyometric exercise (Ebben, 2002; Lorenz, 2011; Scott, Ditroilo, \& Marshall, 2016). Accordingly, aware and accurate selection of biomechanically similar exercises when designing complex training programs should be carefully considered by coaches (Scott et al., 2016). Theoretically, heavy load resistance exercise (1-5RM) stimulates the neurological, muscular, and psychomotor system characteristics to allow the player's muscles to generate more power on the subsequent biomechanically similar comparable plyometric exercise (Baker, 2003; Bevan, Owen, Cunningham, Kingsley, \& Kilduff, 2009; Hrysomallis \& Kidgell, 2001; Young, Jenner, \& Griffiths, 1998). More precisely, during CT exercises the 
stimulation of motor unit excitability may increase motor unit mobilization, synchronization and phosphorylation of the myosin light chain, that increase the myofilaments sensitivity to calcium, which have a functional role in increasing the rate of force production during rapid muscle contractions (Hodgson, Docherty, \& Robbins, 2005; Semmler, 2002). Furthermore, CT is supported by post-activation potentiation (PAP) which primarily defined by Robbins as a phenomenon by which the force exerted by a muscle is influenced by the previous contractile history of this muscle (Carter \& Greenwood, 2014; Hamada, Sale, MacDougall, \& Tarnopolsky, 2000; Lorenz, 2011; Robbins, 2005; Sale, 2002; Scott et al., 2016; Wren, Yerby, Beaupr E, \& Carter, n.d.). In other words, excitation potential across the spinal cord can be increased by muscle pre-contraction, which resulting in increased motor unit recruitment (Kilduff et al., 2007). As a result of this excitation, postsynaptic potentials increases by lasting several minutes and enhance force production during the subsequent performance (Chen, Lo, Wang, Yu, \& Peng, 2017). Although previous studies have reported that a heavy load pre-contraction produces PAP, it also induces muscular fatigue, which means that the subsequent muscular achievement depends on the balance between PAP and fatigue (Bevan et al., 2009; Kilduff et al., 2007). Thus, the time of rest interval between the heavy load pre-contraction and the subsequent performance should be determined individually (Chen et al., 2017; THOMAS M. COMYNS, ANDREW J. HARRISON, LIAM K. HENNESSY, \& RANDALL L. JENSEN, 2006). Heading the ball form jumping as a power oriented skill is one of the most important skills for soccer players. It demands sprinting and jumping with short ground contact times and achieving maximum jumping height or rabid movements, which are strongly needed for an optimal performance (Phillips \& Flanagan, 2015; Sáez de Villarreal, Requena, \& Cronin, 2012). Different training strategies were designed to enhance power performance for male and female athletes including soccer juniors and players, such as resistance exercises (Chelly et al., 2009; Christou et al., 2006; Jullien et al., 2008; López-Segovia, Palao Andrés, \& González-Badillo, 2010), 
plyometric exercises (Chaabene \& Negra, 2017; Chelly et al., 2010; Meylan \& Malatesta, 2009; Ozbar, Ates, \& Agopyan, 2014; Ramírez-Campillo et al., 2014, 2015; Váczi, Tollár, Meszler, Juhász, \& Karsai, 2013) and complex training (Bevan et al., 2009; Carter \& Greenwood, 2014; Maio Alves, Rebelo, Abrantes, \& Sampaio, 2010; Scott et al., 2016). Previous studies also compared between the effect of CT, $\mathrm{PT}$, and resistance exercises (RE) on PAP, specific performance, vertical jump performance (VJ), specific performance (Chen et al., 2017; da Silva Santos, Valenzuela, \& Franchini, 2015; MacDonald, Lamont, \& Garner, 2012; Miarka, Del Vecchio, \& Franchini, 2011).

Heading the ball from jumping as a power oriented move is in a great importance for soccer players. Reaching a maximum height with minimum ground contact time and longer flight time gives the soccer player an advantage to reach the ball in a higher point to score a goal. Therefore, the aim of the present study is to investigate a) the effect of 8 weeks of $\mathrm{CT}$ on ground contact time, jumping height, time to reach maximum height, and total flight time during heading the ball for soccer players b) effect of complex training on SJ height and CMJ height. It is hypothesized that 8 week complex training program would improve ground contact time, jumping height, and flight time during heading the ball for soccer players and also increase both SJ and CMJ heights.

\section{METHODS}

The experimental method was used on a sample of ten participants physical active healthy males soccer players of Mansoura sport club (mean +/- SD: $20.7+/-1.2$ years, $176.5+/-7.3 \mathrm{~cm}, 76.5+/-6.7 \mathrm{~kg}$ ) in this study by applying pre and post measurements. The subjects were informed about testing procedure as a group to be sure that they all get the same instructions. Pre and post measurements were applied after a standardized warm-up program. 
Pre-measurements: Subjects were asked to perform Squat jumping test and Countermovement jumping test. Furthermore, subjects were asked to perform heading the ball from jumping after approach of two running steps. Every subject was given three trials for every test and the best try in height was recorded in the test protocol. All the trials were recorded using high frequency video camera (Gopro3 Black edition, $240 \mathrm{fps})$.

Squat jump height measurement: All subjects were asked to wear black tight leggings and were marked with a green phosphorus tick on the hip joints over the tight leggings. Subjects were informed about the SJ instructions which were:

- Stand straight resting your hands on your hips (to measure leg performance instead of arm performance). $\quad$ - Stand straight up for 1-2 seconds

- Then go to squat position (knees bent to $90^{\circ}$ ) and stand still for 1-2 seconds

- Jump as high as you can without making any countermovement before takeoff.

- Land with normal flexion and stand still in neutral position for 1-2 seconds. The height was determined using (Tracker 4.96 video analysis and modeling tool for physics education) by moving the video (frame by frame) till the player stands on his toes then measuring the distance from the mark to the ground directly before the jump. After that the video was moved again (frame by frame) till the player reached the maximum height then measuring the distance from the mark to the ground. The two distances were subtracted to obtain the maximum SJH.

Countermovement jump measurement: Subjects were informed about the CMJ instructions which were:

Stand straight resting your hands on your hips (to measure leg performance instead of arm performance). $\quad$ - Stand straight up for 1-2 seconds.

Jump as high as you can then land with normal flexion and stand still in neutral position for 1-2 seconds. Maximum Countermovement height was determined using the same way that used with the SJH. 
Maximum jumping height measurement: Subjects were asked to perform heading the ball from jumping after approach of two steps. Jumping height was determined by analyzing the video using (Tracker 4.96 video analysis and modeling tool for physics education). Jumping height was determined using the same way as described in SJH.

(a)
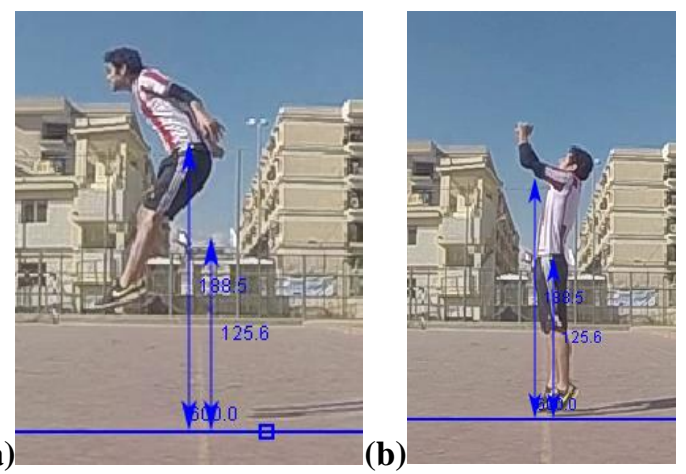

Fig.1. Measurement of maximum jumping height

Calculation of the GCT: Ground contact time was calculated using the equation $((\Delta \mathrm{t}=$ $1 / 0.24 \times$ frames) depending on the camera frequency which is $240 \mathrm{~Hz}$. The frames, which the player's feet contacted with the ground during the take-off were counted and used in the equation $(\Delta t=(1 / 0.24) \times$ frames $)$ to obtain the ground contact time in milliseconds. For example, if the numbers of the frames is 47 , the ground contact time will be $\Delta \mathrm{t}=(1 / 0.24) \times 47=195.83 \mathrm{~ms}$.

Calculation of flight time: Flying time was calculated using the equation

$\mathrm{t}^{2}=$ Height meters $/(0.5 \times$ Gravity $) \quad \mathrm{t}^{2}=$ Height meters $/\left(0,5 \times 9,8 \mathrm{~m} / \mathrm{s}^{2}\right)$

$\mathrm{t}=\operatorname{sqrt}($ Height meters $/(0,5 \times 9,8)) \quad \mathrm{t}=$ seconds (time to reach maximum height) $2 \times \mathrm{t}=$ seconds (total flight time)

Calculation of Velocity: Velocity was calculated using the following equation.

Velocity $=$ Gravity $\times$ time to reach maximum height.

Training program: The eight week complex training program was applied three times a week during the specific preparation phase. Boxes and hurdle height which used for the plyometric exercises was determined $(40-60 \mathrm{~cm})$. CT alternates between sets of weight exercises for lower extremity (2 sets of 3-8 repetitions $70-95 \%$ of $1 \mathrm{RM}$ ) and 2 
sets of 6-10 repetitions of plyometric jumps (ex. depth jumps) in the same training session with rest interval ranging between 2-3 minutes (table1).

Table 1. Complex Training Program

\begin{tabular}{|c|c|c|c|}
\hline $\begin{array}{c}\text { Days } \\
\text { Weeks }\end{array}$ & Day 1 & Day 2 & Day 3 \\
\hline Week 1 & $\begin{array}{l}-2 \times 8 \text { Back squat at } 70 \% 1 \mathrm{RM} \\
-2 \times 6 \text { Squat jump }\end{array}$ & $\begin{array}{l}-2 \times 8 \text { Standing calf raise at } 70 \% 1 \mathrm{RM} \\
2 \times 8 \text { Depth jump } 40 \mathrm{~cm} .\end{array}$ & $\begin{array}{l}\text { - } 2 \times 8 \text { leg extension at } 70 \% 1 \mathrm{RM} \\
-2 \times 8 \text { Drop jumps } 40 \mathrm{~cm}\end{array}$ \\
\hline Week 2 & $\begin{array}{l}\text { - } 2 \times 8 \text { Single Leg Lunge at } 70 \% 1 \mathrm{RM} \\
\text { - } 2 \times 8 \text { Alternating lunge jump. }\end{array}$ & $\begin{array}{l}\text { - } 2 \times 8 \text { Single leg standing calf raise at } \\
70 \% 1 \mathrm{RM} \\
-2 \times 8 \text { single leg depth jumps } 20 \mathrm{~cm} \\
\text { box. }\end{array}$ & $\begin{array}{l}-2 \times 8 \text { leg curl at } 70 \% 1 \mathrm{RM} \\
-2 \times 8 \text { single leg Hurdle jumps } 30 \\
\mathrm{~cm} .(4 \text { Hurdles) }\end{array}$ \\
\hline Week 3 & $\begin{array}{l}-2 \times 8 \text { Leg press at } 70 \% 1 \mathrm{RM} \\
-2 \times 10 \text { Box jump }(50 \mathrm{~cm} .)\end{array}$ & $\begin{array}{l}-2 \times 6 \text { Split squat at } 80 \% 1 \mathrm{RM} \\
-2 \times 10 \text { Split squat jump }\end{array}$ & $\begin{array}{l}-2 \times 6 \text { Step up at } 80 \% 1 \mathrm{RM}(40 \mathrm{~cm} \\
\text { box }) \\
-2 \times 8 \text { Step up jumps }\end{array}$ \\
\hline Week 4 & $\begin{array}{l}\text { - } 1 \times 6 \text { Back squat at } 80 \% 1 \mathrm{RM} \\
-1 \times 8 \text { vertical hurdle jump (4Hurdles) } \\
-1 \times 6 \text { at } 80 \% \text { 1RM Single Leg Lunge } \\
-1 \times 8 \text { Alternating lunge jump. }\end{array}$ & $\begin{array}{l}\text { - } 1 \times 6 \text { Standing calf raise at } 80 \% 1 \mathrm{RM} \\
-1 \times 10 \text { depth jumps to a second box } \\
40 \mathrm{~cm} \\
-1 \times 5 \text { at } 85 \% 1 \text { RM Split squat } \\
-1 \times 5 \text { Split squat jumps followed by } 5 \\
\text { vertical hurdle jumps }(40 \mathrm{~cm} \text {.) }\end{array}$ & $\begin{array}{l}\text { - } 1 \times 6 \text { leg extension at } 80 \% 1 \mathrm{RM} \\
-1 \times 10 \text { Box jump } 40 \mathrm{~cm} . \\
-1 \times 6 \text { at } 80 \% 1 \mathrm{RM} \text { leg curl } \\
-1 \times 10 \text { vertical side hurdle jumps } 40 \\
\text { cm.(4Hurdles) }\end{array}$ \\
\hline Week 5 & $\begin{array}{l}-1 \times 8 \text { leg press at } 70 \% 1 \mathrm{RM} \\
-1 \times 8 \text { box jump }(50 \mathrm{~cm}) \text { then depth } \\
\text { jumps to a second box } 40 \mathrm{~cm} . \\
-1 \times 6 \text { Single Leg Lunge at } 80 \% 1 \mathrm{RM} \\
-1 \times 10 \text { Alternating lunge jump. }\end{array}$ & $\begin{array}{l}\text { - } 1 \times 5 \text { Standing calf raise at } 85 \% 1 \mathrm{RM} \\
-1 \times 8 \text { side depth jump } 50 \mathrm{~cm} \text {. } \\
\text { followed by side jumping over } 4 \\
\text { hurdles } 40 \mathrm{~cm} . \\
-1 \times 6 \text { leg curl at } 80 \% 1 \mathrm{RM} \\
-1 \times 6 \text { vertical countermovement jumps } \\
\text { followed by heading the ball from } \\
\text { jumping. }\end{array}$ & $\begin{array}{l}\text { - } 1 \times 5 \text { Step up at } 85 \% \text { RM }(40 \mathrm{~cm} \\
\text { box) } \\
\text { - } 1 \times 8 \text { Step up jumps } \\
\text { - } 1 \times 5 \text { leg extension at } 85 \% 1 \mathrm{RM} \\
\text { - } 1 \times 8 \text { single leg side hurdle jumps } 40 \\
\mathrm{~cm} \text {. (4Hurdles) followed by heading } \\
\text { the ball from jumping. }\end{array}$ \\
\hline Week 6 & $\begin{array}{l}\text { - } 1 \times 5 \text { Split squat at } 85 \% 1 \mathrm{RM} \\
\text { - } 1 \times 8 \text { Split squat jump then } 2 \text { vertical } \\
\text { hurdle jumps } \\
\text { - } 1 \times 4 \text { Standing calf raise at } 90 \% 1 \mathrm{RM} \\
-1 \times 10 \text { depth jumps to a second box } \\
40 \mathrm{~cm} \text { then } 3 \text { vertical hurdle jumps. }\end{array}$ & $\begin{array}{l}\text { - } 1 \times 4 \text { Back squat at } 90 \% 1 \mathrm{RM} \\
-1 \times 8 \text { backward depth jump } 45 \mathrm{~cm} \text {. } \\
-1 \times 6 \text { leg press at } 80 \% 1 \mathrm{RM} \\
-1 \times 10 \text { Box jump }(50 \mathrm{~cm} .) \text { to depth } \\
\text { jump then } 2 \text { hurdle vertical jumps. }\end{array}$ & $\begin{array}{l}\text { - } 1 \times 4 \text { Step up at } 90 \% 1 \mathrm{RM}(40 \mathrm{~cm} \\
\text { box }) \\
\text { - } 1 \times 8 \text { Step up jumps } \\
\text { - } 1 \times 4 \text { Standing calf raise at } 90 \% 1 \mathrm{RM} \\
\text { - } 2 \times 10 \text { side depth jump followed by } 3 \\
\text { Hurdle jumps then heading the ball } \\
\text { from jumping. }\end{array}$ \\
\hline Week 7 & $\begin{array}{l}\text { - } 1 \times 4 \text { leg extension at } 90 \% 1 \mathrm{RM} \\
-1 \times 8 \text { depth jump to second box to } \\
\text { drop jump } 40 \mathrm{~cm} \\
-1 \times 4 \text { leg curl at } 90 \% 1 \mathrm{RM} \\
-1 \times 6 \text { single leg hurdle jump } 30 \\
\text { cm.(4Hurdles) }\end{array}$ & $\begin{array}{l}\text { - } 1 \times 4 \text { leg press at } 90 \% 1 \mathrm{RM} \\
-1 \times 6 \text { box jump }(60 \mathrm{~cm}) \text { then depth } \\
\text { jumps to a second box } 40 \mathrm{~cm} . \\
-1 \times 4 \text { leg extension at } 90 \% 1 \mathrm{RM} \\
-1 \times 10 \text { Box jump } 40 \mathrm{~cm} \text { to drop jump. }\end{array}$ & $\begin{array}{l}\text { - } 1 \times 4 \text { at } 90 \% 1 \text { RM Split squat } \\
-1 \times 6 \text { Split squat jumps followed by } 2 \\
\text { vertical hurdle jumps }(40 \mathrm{~cm} \text {.) then } 2 \\
\text { side vertical hurdle jumps. } \\
-1 \times 4 \text { Back squat at } 90 \% 1 \text { RM } \\
-1 \times 4 \text { vertical hurdle jump ( } 4 \text { Hurdles) } \\
\text { then box jump ( } 40 \mathrm{~cm}) \text { to depth jump } \\
\text { to vertical jump to head the ball. }\end{array}$ \\
\hline Week 8 & $\begin{array}{l}\text { - } 1 \times 3 \text { Standing calf raise at } 95 \% 1 \mathrm{RM} \\
-1 \times 6 \text { depth jumps to a second box } 40 \\
\mathrm{~cm} \\
-1 \times 3 \text { Single Leg Lunge at } 95 \% 1 \mathrm{RM} \\
-1 \times 6 \text { Alternating lunge jump then box } \\
\text { jump to depth jump to head the ball. }\end{array}$ & $\begin{array}{l}-1 \times 3 \text { Step up at } 95 \% 1 \mathrm{RM}(40 \mathrm{~cm} \\
\text { box) } \\
-1 \times 8 \text { Step up jumps } \\
-1 \times 3 \text { Back squat at } 95 \% 1 \mathrm{RM} \\
-1 \times 4 \text { vertical hurdle jump ( } 4 \text { Hurdles) } \\
\text { then box jump (40cm) to depth jump } \\
\text { to vertical jump to head the ball. }\end{array}$ & $\begin{array}{l}\text { - } 1 \times 3 \text { leg curl at } 95 \% 1 \mathrm{RM} \\
-1 \times 6 \text { single leg hurdle jump } 30 \\
\mathrm{~cm} .(4 \text { Hurdles) } \\
\text { - } 1 \times 3 \text { Split squat at } 95 \% 1 \mathrm{RM} \\
\text { - } 1 \times 8 \text { Split squat jump then } 2 \text { vertical } \\
\text { hurdle jumps then vertical jump to } \\
\text { head the ball. }\end{array}$ \\
\hline
\end{tabular}

Post-measurements: The post measurements were applied on the subjects following the same procedures that followed in the pre measurements.

Statistical analysis: SPSS (version 16.0, SPSS) was used for the statistical analyses.

Means and standard deviations are presented. Paired Sample $\mathbf{T}$ test were calculated for the differences between the pre and post measurements for the measured variables, p-value is less than 0.05 was defined for statistical significance.

\section{RESULTS}

Table (2) Means, Standard Deviation, and t test of the measured variables 


\begin{tabular}{|c|c|c|c|c|}
\hline \multirow{2}{*}{ Variables } & Pre-Measurements & Post-Measurements & \multirow{2}{*}{$\mathrm{t}$} & \multirow{2}{*}{$\begin{array}{l}\text { Sig. (2- } \\
\text { tailed) }\end{array}$} \\
\hline & Mean \pm Stdv. & Mean \pm Stdv & & \\
\hline Jumping Height during heading(JHDH) $\mathrm{cm}$ & $52.46 \pm 6.32$ & $57.26 \pm 6.33$ & $5.05^{*}$ & .000 \\
\hline Total Flight time during heading (TFT) ms & $0.653 \pm 0.0391$ & $0.683 \pm 0.0387$ & $-4.895 *$ & .001 \\
\hline Time to reach maximum height (TMH)ms & $0.341 \pm 0.0193$ & $0.327 \pm 0.0195$ & $-4.895 *$ & .001 \\
\hline Initial Velocity (IV) & $3.201 \pm 0.192$ & $3.345 \pm 0.187$ & $-4.895 *$ & .001 \\
\hline Ground contact time (GCT) ms & $251.6 \overline{7} \pm 40.26$ & $215.0 \pm 36.12$ & $5.56^{*}$ & .000 \\
\hline Squat jump height $(\mathrm{SJH}) \mathrm{cm}$ & $37.5 \pm 4.00$ & $40.85 \pm 4.25$ & $11.79 *$ & .000 \\
\hline Countermovement jump height $(\mathrm{CMJH}) \mathrm{cm}$ & $39.60 \pm 3.72$ & $44.68 \pm 4.28$ & $6.30 *$ & .000 \\
\hline
\end{tabular}

*Significant at $(p<0.05)$

After 8 weeks of CT program, the main results observed were as follows: statistical significant differences $(t=5.05),(p \leq 0.05)$ between pre and post measurements for the post measurements in jumping height during heading; an increase in total flight time during heading between the pre and post measurements $(\mathrm{t}=-4.895),(p \leq 0.05)$ for the post measurements; a significant reduction of the time to reach maximum height $(\mathrm{t}=$ $4,895)(p \leq 0.05)$ for the post measurements; a significant increase of initial velocity for the post measurement; a significant reduction of the ground contact time between the pre and post measurements $(\mathrm{t}=5.558),(p \leq 0.05)$ for the post measurements; an increase in both squat jump height and countermovement jump height between the pre and post measurements $(\mathrm{t}=11.79),(\mathrm{t}=11.79)$, respectively $(p \leq 0.05)$ for the post measurements (Table 2) .

\section{DISCUSSION}

The aim of the present study was to identify the effect of an 8-week CT program on jumping height, flight time, ground contact time during heading the ball, Squat jump height and counter movement jump height. Results showed that the main hypothesis of the research was proved. After the $\mathrm{CT}$ program an increase in jumping height and flight time during heading the ball, also an increase in SJ height and CMJ height were found, while there was a reduction in GCT during jumping to head the ball. This improvement may be due to the CT program, which alternates between sets of weight exercises for lower extremity (2 sets of 3-8 repetitions 70-90\% of $1 \mathrm{RM}$ ) and 2 sets of 8-10 repetitions of plyometric jumps (ex. depth jumps) in the same training session with rest interval ranging between 2-3 minutes. Weight exercises with maximum or 
near maximum resistance may increase synchronization of motor unit recruitment (EBBEN, JENSEN, \& BLACKARD, 2000), which may be effectively used during the subsequent plyometric exercises and make it more efficient in minimizing the ground contact time and achieving a maximum height. Furthermore, during plyometric exercises the involvement of the stretch-shortening cycle (SSC) allows muscle to store elastic energy during the deceleration phase and release it later during the shortening positive phase enhancing muscle force and power output (Markovic \& Mikulic, 2010; Ramírez-Campillo et al., 2015). Practically, The simultaneous work of the activated motor units after heavy load resistance exercises with the elastic energy of the muscle-tendon unit gained in the shortenings' phase of the stretch-shortening cycle during plyometric exercises may be the reason of the increased power output (Baker, 2003; de Hoyo et al., 2016; Ramírez-Campillo et al., 2015). Results of the present study agreed with (Kobal et al., 2016) who found significant improvement after a comparative study in vertical jump (countermovement jump) and speed after 8 weeks of CT for elite young soccer players. The present results show $4.8 \mathrm{~cm}$ increase of JHDH, $3.35 \mathrm{~cm}$ increase of $\mathrm{SJH}, 5.08 \mathrm{~cm}$ increase of $\mathrm{CMJ}$, and $0.03 \mathrm{~s}$ increase of TFT during heading the ball, while there were $0.014 \mathrm{~s}$ reduction of TMH and $36.67 \mathrm{~ms}$ reduction of the GCT. The players who participated in the study were monitored during first three matches of the competitions phase. They showed better performance in the situations which need dealing with high balls with their heads to score goals or passing to their team mates or heading the ball away from their own goalkeepers' area. These findings agreed with (Maio Alves et al., 2010) who found a reduction in sprint times over 5 and $15 \mathrm{~m}$ and an increase on squat and vertical jump performance for soccer players. (Miarka et al., 2011) who found significant improvement in specific judo performance after CT (execution of three sets of two repetitions of the player's 90\% 1 RM squat followed by five consecutive jumps) and RE (five sets of one squat repetition at 95\% $1 \mathrm{RM}$ ). (da Silva Santos et al., 2015) found improvement in taekwondo specific performance test after combining three sets of half-squat each 
consists of two repetitions with $95 \%$ of 1RM followed by four vertical jumps. (MacDonald et al., 2012) reported in a comparison study between CT, traditional resistance training, and plyometric training, that $\mathrm{CT}$ reflects benefits of both traditional RT and PT, which make CT an applicable training modality. (Ingle, Sleap, \& Tolfrey, 2006) reported improvrment in power, jumping and sprinting performance after complex training for upper and lower body for pre- and early pubertal boys.

According to these aforementioned findings and the results of the present study, it was suggested that the complex training is an appropriate training design to induce power production and improve vertical jump height and sprint performance for soccer players. The effect of CT on the PAP is still unclear and need more investigation.

\section{Conclusion}

This study has shown that an 8 week CT program increases JHDH, TFT, IV during heading the ball, SJ height, and CMJ height and reduction of GCT and TMH while jumping to head the ball. As a consequence, the present results recommend involving complex training exercises in the specific preparation phase for soccer players. We could conclude that complex training program increases jumping performances by improving both motor units recruitment after heavy resistance weight exercises and the stored energy in the muscle tendon unite during the shortening phase of the involved muscles during plyometric exercises. However, further studies should investigate the effect of different strategies and intensities of complex training on explosive power and post-activation potentiation for both upper and lower extremity.

\section{References}

1. Baker, D. (2003). Acute effect of alternating heavy and light resistances on power output during upper-body complex power training. Journal of Strength and Conditioning Research, 17(3), 493-7. Retrieved from

2. Bevan, H. R., Owen, N. J., Cunningham, D. J., Kingsley, M. I., \& Kilduff, L. P. (2009). Complex Training in Professional Rugby Players: Influence of Recovery Time on Upper-Body Power Output. Journal of Strength and Conditioning Research, 23(6), 1780-1785.

3. Carter, J., \& Greenwood, M. (2014). Complex Training Reexamined. Strength and Conditioning Journal, 36(2), 11-19. 
4. Chaabene, H., \& Negra, Y. (2017). The Effect of Plyometric Training Volume in Prepubertal Male Soccer Players' Athletic Performance. International Journal of Sports Physiology and Performance, 1-22. http://doi.org/10.1123/ijspp.2016-0372

5. Chelly, M. S., Fathloun, M., Cherif, N., Amar, M. Ben, Tabka, Z., \& Van Praagh, E. (2009). Effects of a Back Squat Training Program on Leg Power, Jump, and Sprint Performances in Junior Soccer Players. Journal of Strength and Conditioning Research, 23(8), 2241-2249.

6. Chelly, M. S., Ghenem, M. A., Abid, K., Hermassi, S., Tabka, Z., \& Shephard, R. J. (2010). Effects of in-Season Short-Term Plyometric Training Program on Leg Power, Jump- and Sprint Performance of Soccer Players. Journal of Strength and Conditioning Research, 24(10), 2670-2676.

7. Chen, Z.-R., Lo, S.-L., Wang, M.-H., Yu, C.-F., \& Peng, H.-T. (2017). Can Different Complex Training Improve the Individual Phenomenon of PostActivation Potentiation? Journal of Human Kinetics, 56(56), 167-175.

8. Christou, M., Smilios, I., Sotiropoulos, K., Volaklis, K., Pilianidis, T., \& Tokmakidis, S. P. (2006). Effects of Resistance Training on the Physical Capacities of Adolescent Soccer Players. The Journal of Strength and Conditioning Research, 20(4), 783.

9. da Silva Santos, J. F., Valenzuela, T. H., \& Franchini, E. (2015). Can Different Conditioning Activities and Rest Intervals Affect the Acute Performance of Taekwondo Turning Kick? Journal of Strength and Conditioning Research, 29(6), 1640-1647.

10. de Hoyo, M., Gonzalo-Skok, O., Sañudo, B., Carrascal, C., Plaza-Armas, J. R., Camacho-Candil, F., \& Otero-Esquina, C. (2016). Comparative Effects of In-Season Full-Back Squat, Resisted Sprint Training, and Plyometric Training on Explosive Performance in U-19 Elite Soccer Players. Journal of Strength and Conditioning Research, 30(2), 368-377.

11. Docherty, D., Robbins, D., \& Hodgson, M. (2004). Complex Training Revisited: A Review of its Current Status a... : Strength \&amp; Conditioning Journal. Strength \& Conditioning Journal, 26(6), 52-57. Retrieved from

12. Ebben, W. (2002). Complex Training: a Brief Review. Journal of Sports Science \& Medicine. Retrieved from http://epublications.marquette.edu/exsci_fac/67

13. Ebben, W. P. ., Jensen, R. L. ., \& Blackard, D. O. (2000). Electromyographic and Kinetic Analysis of Complex Training Variables. Journal of Strength \& Conditioning Research, 14(4), 451-456. Retrieved from

14. Faude, O., Koch, T., \& Meyer, T. (2012). Straight sprinting is the most frequent action in goal situations in professional football. Journal of Sports Sciences, 30(7), 625-631.

15. Fleck, S. C. S. C. S. ., \& Kontor, K. C. S. C. S. (1986). SOVIET STRENGTH AND CONDITIONING: Complex training.: Strength \&amp; Conditioning Journal. National Strength \& Conditioning Association Journal, 8(5), 66-72.

16. Hamada, T., Sale, D. G., MacDougall, J. D., \& Tarnopolsky, M. A. (2000). Postactivation potentiation, fiber type, and twitch contraction time in human knee extensor muscles. Journal of Applied Physiology (Bethesda, Md. : 1985), $88(6), 2131-7$.

17. Hodgson, M., Docherty, D., \& Robbins, D. (2005). Post-activation potentiation: underlying physiology and implications for motor performance. Sports Medicine (Auckland, N.Z.), 35(7), 585-95. 
18. Hrysomallis, C., \& Kidgell, D. (2001). Effect of heavy dynamic resistive exercise on acute upper-body power. Journal of Strength and Conditioning Research, 15(4), 426-30.

19. Ingle, L., Sleap, M., \& Tolfrey, K. (2006). The effect of a complex training and detraining programme on selected strength and power variables in early pubertal boys. Journal of Sports Sciences, 24(9), 987-997.

20. Jullien, H., Bisch, C., Largouët, N., Manouvrier, C., Carling, C. J., \& Amiard, V. (2008). Does A Short Period of Lower Limb Strength Training Improve Performance in Field-Based Tests of Running and Agility in Young Professional Soccer Players? Journal of Strength and Conditioning Research, 22(2), 404-411.

21. Kilduff, L. P., Bevan, H. R., Kingsley, M. I. C., Owen, N. J., Bennett, M. A., Bunce, P. J., ... Cunningham, D. J. (2007). Postactivation Potentiation in Professional Rugby Players: Optimal Recovery. The Journal of Strength and Conditioning Research, 21(4), 1134.

22. Kobal, R., Loturco, I., Barroso, R., Gil, S., Cuniyochi, R., Ugrinowitsch, C., ... Tricoli, V. (2016). Effects Of Different Combinations Of Strength, Power, And Plyometric Training On The Physical Performance Of Elite Young Soccer Players. Journal of Strength and Conditioning Research, 1.

23. López-Segovia, M., Palao Andrés, J. M., \& González-Badillo, J. J. (2010). Effect of 4 Months of Training on Aerobic Power, Strength, and Acceleration in Two Under-19 Soccer Teams. Journal of Strength and Conditioning Research, 24(10), 2705-2714.

24. Lorenz, D. (2011). Postactivation potentiation: an introduction. International Journal of Sports Physical Therapy, 6(3), 234-40.

25. MacDonald, C. J., Lamont, H. S., \& Garner, J. C. (2012). A Comparison of the Effects of 6 Weeks of Traditional Resistance Training, Plyometric Training, and Complex Training on Measures of Strength and Anthropometrics. Journal of Strength and Conditioning Research, 26(2), 422-431.

26. Maio Alves, J. M. V., Rebelo, A. N., Abrantes, C., \& Sampaio, J. (2010). Short-Term Effects of Complex and Contrast Training in Soccer Players' Vertical Jump, Sprint, and Agility Abilities. Journal of Strength and Conditioning Research, 24(4), 936-941.

27. Markovic, G., \& Mikulic, P. (2010). Neuro-Musculoskeletal and Performance Adaptations to Lower-Extremity Plyometric Training. Sports Medicine, 40(10), 859-895.

28. Meylan, C., \& Malatesta, D. (2009). Effects of In-Season Plyometric Training Within Soccer Practice on Explosive Actions of Young Players. Journal of Strength and Conditioning Research, 23(9), 2605-2613.

29. Miarka, B., Del Vecchio, F. B., \& Franchini, E. (2011). Acute Effects and Postactivation Potentiation in the Special Judo Fitness Test. Journal of Strength and Conditioning Research, 25(2), 427-431.

30. Newton, R. U., Kraemer, W. J., Häkkinen, K., Humphries, B. J., \& Murphy, A. J. (1996). Kinematics, Kinetics, and Muscle Activation during Explosive Upper Body Movements. Journal of Applied Biomechanics, 12(1), 31-43.

31. Newton, R. U., Murphy, A. J., Humphries, B. J., Wilson, G. J., Kraemer, W. J., \& Häkkinen, K. (1997). Influence of load and stretch shortening cycle on the kinematics, kinetics and muscle activation that occurs during explosive upper-body movements. European Journal of Applied Physiology, 75(4), 333342. 
32. Ozbar, N., Ates, S., \& Agopyan, A. (2014). The Effect of 8-Week Plyometric Training on Leg Power, Jump and Sprint Performance in Female Soccer Players. Journal of Strength and Conditioning Research, 28(10), 2888-2894.

33. Phillips, J. H., \& Flanagan, S. P. (2015). Effect of Ankle Joint Contact Angle and Ground Contact Time on Depth Jump Performance. Journal of Strength and Conditioning Research, 29(11), 3143-3148.

34. Ramírez-Campillo, R., Álvarez, C., Henríquez-Olguín, C., Baez, E. B., Martínez, C., Andrade, D. C., \& Izquierdo, M. (2014). Effects of Plyometric Training on Endurance and Explosive Strength Performance in Competitive Middle- and Long-Distance Runners. Journal of Strength and Conditioning Research, 28(1), 97-104.

35. Ramírez-Campillo, R., Gallardo, F., Henriquez-Olguín, C., Meylan, C. M. P., Martínez, C., Álvarez, C., ... Izquierdo, M. (2015). Effect of Vertical, Horizontal, and Combined Plyometric Training on Explosive, Balance, and Endurance Performance of Young Soccer Players. Journal of Strength and Conditioning Research, 29(7), 1784-1795.

36. Robbins, D. W. (2005). Postactivation Potentiation and Its Practical Applicability: A Brief Review. The Journal of Strength and Conditioning Research, 19(2), 453.

37. Sáez de Villarreal, E., Requena, B., \& Cronin, J. B. (2012). The Effects of Plyometric Training on Sprint Performance: A Meta-Analysis. Journal of Strength and Conditioning Research, 26(2), 575-584.

38. Sale, D. G. (2002). Postactivation potentiation: role in human performance. Exercise and Sport Sciences Reviews, 30(3), 138-43.

39. Scott, D. J., Ditroilo, M., \& Marshall, P. (2016). Complex training: The effect of exercise selection and training status on post-activation potentiation in rugby league players. Journal of Strength and Conditioning Research, 1.

40. Semmler, J. G. (2002). Motor unit synchronization and neuromuscular performance. Exercise and Sport Sciences Reviews, 30(1), 8-14.

41. THOMAS M. COMYNS, ANDREW J. HARRISON, LIAM K. HENNESSY, \& RANDALL L. JENSEN. (2006). THE OPTIMAL COMPLEX TRAINING REST INTERVAL FOR ATHLETES FROM ANAEROBIC SPORTSnal Link. Journal of Strength \& Conditioning Research, 20(3), 471-476.

42. Váczi, M., Tollár, J., Meszler, B., Juhász, I., \& Karsai, I. (2013). Short-term high intensity plyometric training program improves strength, power and agility in male soccer players. Journal of Human Kinetics, 36, 17-26.

43. Wilson, G. J., Wood, G. A., \& Elliott, B. C. (1991). Optimal stiffness of series elastic component in a stretch-shorten cycle activity. Journal of Applied Physiology (Bethesda, Md. : 1985), 70(2), 825-33.

44. Wren, T. A. L., Yerby, S. A., Beaupr E, G. S., \& Carter, D. R. (n.d.). Mechanical properties of the human achilles tendon.

45. Young, W., Jenner, A., \& Griffiths, K. (1998). Acute Enhancement of Power Performance From Heavy Load Squat... .. Journal of Strength \& Conditioning Research, 12(2), 82-88. 